\title{
Bringing Conviviality into Methods in Media and Migration Studies
}

Erin Cory

\section{INTRODUCTION}

In this chapter, I explore the potentials of conviviality as a methodological tool for studying media, broadly conceived, in a migration context. I draw on a research project in which conviviality works as a prism to understand media practices related to migration and refugees. Based on anecdotes from the field and through consideration of the dialectic between analysis and method, I discuss how the concept is best appropriated as a methodological tool in research designs informing current and future activist-based studies in this area.

As I elucidate in this chapter, conviviality conveys a deep concern with how we understand different modes of human connection, and it possesses a renewed charge in the context of the refugee migration of 2015 and its aftermath. This notion of conviviality includes a variety of different perspectives, including living with difference, mutuality, and togetherness, valences of the term still being unpacked in current scholarship. Within the literature, however, there exists little thinking on the methodological

E. Cory $(\varangle)$

Faculty of Culture and Society, Malmö University, Malmö, Sweden

e-mail: erin.cory@mau.se

(C) The Author(s) 2020

O. Hemer et al. (eds.), Conviviality at the Crossroads, https://doi.org/10.1007/978-3-030-28979-9_8 
possibilities of conviviality. In other words, what can conviviality $d o$, or rather, what can researchers do with it in efforts to understand the crucial connections between media, mediation, and migration? How, further, can researchers across disciplines do conviviality as part of an interventionist research praxis, the ethical imperatives of which are increasingly hard to ignore?

I begin with a review of the state of the field in media and migration studies before making a case for conviviality as a methodological practice. To illustrate and qualify this argument, I turn to a case study, an ethnographic research project on a social space for refugees and asylum seekers in Copenhagen, where I have been involved for nearly two years. I use this case study to lay out three features that I consider most germane to social justiceoriented media research: conviviality as an ethical position; conviviality as co-production; and the significance of conflict to ongoing commitments to conviviality both inside and outside the research moment.

\section{Media, Mediation, and Migration: State of the Field}

The last few years have been rife with public discussions and several strands of research related to the connections between media and migration. Studies related to news coverage have compared, for example, how local, national, and transnational accounts of immigration phenomena differ (Lawlor 2015; Varju and Plaut 2017) and the news trends that emerge in this coverage, including fear and securitisation (Lulle and Ungure 2015; Caviedes 2015), sensationalism (Musaro and Parmiggiani 2017; Greussing and Boomgaarden 2017), and humanitarian concerns (Berry et al. 2015). A review of the last decade's critical research on European media coverage and journalistic practices indicates a persistent pattern of negative representations of migrants, refugees, and asylum seekers. Results show that such groups are predominantly framed as 'security, economic and hygienic threats' to European populations (Abid et al. 2017), through binary frames as victims and intruders (Van Gorp 2005) or seen to bring about 'societal system collapse' (Matthews and Brown 2012). Others have looked at the recurring use of water metaphors (such as floods or waves) to describe refugees, depicting them as 'an unwelcome natural disaster' in de-humanising ways that leave people devoid of agency (Gabrielatos and Baker 2008; Parker 2015; see also Abid et al. 2017).

Researchers have remained interested in how migrants use media technologies and platforms to negotiate both their movements between places 
and issues related to immigration practicalities and, further on, their identities, upon arrival (Mapping Refugee Media Journeys, Gillespie et al. 2016; Getting to Europe the Whatsapp Way, Frouws et al. 2016).

Much of the work on media and migration privileges extant social, digital, and mass media and in so doing misses the grounded production of migrants themselves. While certainly popular and academic studies of online behaviours and digital communities in diaspora do exist (e.g. Houssein 2013; Dekker and Engbersen 2014), something falls away when human interaction and the research arena are relegated to the digital. One thing this chapter suggests, therefore, is that we think about media more broadly. By considering the city as media (e.g. Kittler and Griffin 1996) and/or studying other physical spaces as media, and by considering the researcher as a media producer, we might better account for the multiple networks (both digital and physical) that overlay and influence each other and catalogue how these networks mediate multiple identities, interactions, and societies.

For the purposes of this chapter, therefore, I deploy broad understandings of media and mediation. The first we might understand simply as the plural form of 'medium', which the Oxford Dictionary of Media and Communication (2016) defines in part as 'any substance or process through which reality is apprehended or constructed'. Similarly, the same volume defines 'mediation' in part as 'the role of any intervening factor in transforming a message, meaning, or experience'.

By examining the media and mediating practices of one migrationrelated local community, I consider how media writ large describe and produce the world, the implications of their production on peoples' lives, and the ethical consequences of research related to these issues. In so doing, I also specifically consider how researchers can both deploy and cultivate conviviality through media-centred activist research praxis.

\section{Conviviality AND/In The Danish ConteXt}

In his argument for considering the possibilities of living with alterity, Gilroy (2006) deploys the notion of conviviality to dismantle holistic notions of 'culture' and 'identity'. A more immediate iteration of 'the planetary'-a term that suggests the movement, expanse, and contingency of identity - conviviality embraces the local disruption of culture, demanding that its purveyors deny 'every notion of culture as property', opting instead 
for a world 'broken and dispersed by the swirling, vertiginous motion of the postcolonial world' (Gilroy 2006: 70).

Of course, Gilroy was writing about postcolonial British melancholia, theorising a redemptive way to break free from the spectres of colonialism and racism by way of a 'radical openness'. And yet these spectres of a racist past, and their persistence in the present, constitute at least an acknowledged part of British history. In the Danish context, such pasts and their legacies are only recently being exhumed from an amnesiac historical narrative (Lapiņa 2016).

The anxiety this uncovering provokes is palpable, registering as a backlash as the Danish state tries to define who belongs to the nation with administrative exactitude - through immigration 'contracts', the construction of a cultural canon, stringent immigration laws, a citizenship test, and political statements like the one issued by the Parliament in 2017, when vast segments of the population were informed that because they did not have 'Western' ancestors, they would never be Danish. The targeted group apparently included Danish-born citizens with non-Western heritage, who have lived most - if not the entirety - of their lives in Denmark.

While the belonging of these citizens hangs in the balance, they still actively contribute to the country. Refugees and asylum seekers, on the other hand, are barred from Denmark's political, social, and cultural identities, even as they are constructed as particular subjects through these very avenues. They are both discursively and visibly excluded from the cultural production about which Gilroy (2004) writes and from the cities teeming with the 'chaotic pleasures of the convivial postcolonial urban world' that he imagines (167). They reside in legal limbo, frequently for years, waiting for information on how to proceed with their hearings, or for a 'positive' decision on their cases. The spaces provided as housing by the Danish state likewise sit at the outer limits of Danish society, many situated at the outskirts of Denmark's smaller towns. Even the 'best' of these, located near Copenhagen so that inhabitants have some access to the city (and often family and friends), do not offer opportunities for cultural engagement. In recent years, the Danish state has begun to close these centres and move inhabitants to Jutland, at the westernmost reaches of the country. With this action, makeshift support systems and communities are being dismantled.

Nevertheless, in the midst of this multiply-rendered isolation, small islands of community, refuge, and conviviality persist. Grassroots organisations dedicated to issues pertaining to new arrivals have sprung up across 
Denmark in recent years, and research interest in them has understandably increased. In the shadow of the social forces that have necessitated the presence of grassroots endeavours, it is imperative that researchers critically consider not only what they are observing in these organisations, but also what their own presence and methods might do to their production.

\section{Conviviality: Empirical, Analytical, METHODOLOGICAL?}

'Conviviality' continues to be debated and theorised in the literature, both as an empirical directive and as an analytical concept. While rehearsing the intricacies of its usage may be repetitive in a volume dedicated to the concept, it is important to note that much of the extant literature focuses on debates regarding conviviality's normative dimensions, often as these relate to its empirical and analytical possibilities and limitations.

As an empirical focus, conviviality calls us to observe the everyday, 'those social phenomena which are not extreme, [but] which are in-between, rather quiet' (Nowicka and Heil 2015: 12-13). Nowicka and Heil propose deploying this characteristic towards an analytical conviviality, through which social situations may be interpreted against the normative grain. The use of analytical conviviality seeks rather to gauge the continuities and changes, the solidarities and conflicts, of everyday life, and in so doing, to release the term from a pretence of togetherness as mere 'sameness' (ibid.: 12-16).

Lapiņa (2016) among others has saliently critiqued conviviality's analytical potential. Her research in Denmark challenges popular discourses of colour blindness which, she argues, attempt to silence the politics of race while simultaneously aggravating inequality (39). Indeed, she proposes that a focus on daily life might actually elide how local convivial situations still reproduce larger inequalities or stereotypes. She argues that a focus on everyday difference still may not take into account the power dynamics that may underpin conviviality - that is, how the idea ultimately benefits some more than others, or whose perspectives disappear in its normative conceptualisation (ibid.).

Taking these ongoing conversations as a springboard, I would like to call attention to the fact that conviviality's methodological possibilities have not yet been sufficiently considered in current work. This seems a source of untapped potential, particularly for action-oriented research, given the 
term's associations with community, difference, and social change. Conviviality's methodological possibilities stem precisely from its apparent capacity to encompass both normativity and conflict in its focus on the manifold interactions that comprise everyday community life.

Consideration of this productive dialectic can be found in contemporary literature on ethnographic methods. Ethnographers (e.g. Fabian 1990; Marcus 1998) have long called for researchers to move beyond work that merely informs. Approaches based on observational reporting run the risk of reproducing asymmetrical power relationships by relying heavily on interlocutors who principally serve as temporary research subjects. A countermeasure would be ethnographers' striving instead for mutuality, 'the promise of nontrivial understanding that is produced by researcher and researched together' (Fabian 1995: 47; qtd. in Alhourani 2017: 212). In the literature on ethnography, this mutuality is described in many ways, including 'speaking to a third' (Marcus 1998) and multivocality (Venegas and Huerta 2010), all phrases that echo conviviality's emphasis on doing everyday life together and living with difference. What might it look like to critically take conviviality to heart in research situations? What if researchers deployed it in projects focused on questioning and dismantling power structures, not only those that span a whole society, but also those located in the research moment?

In describing a research situation in which I was deeply engaged as a participant-observer, I suggest that researchers-particularly ethnographers, whose work illuminates interactions between everyday life and larger structures of influence and power-might harness conviviality towards (1) an ethical position based on aspirations for social change, which nevertheless (2) embraces conflict and ( 3 ) is based on co-production with interlocutors.

\section{Situating Trampoline House}

Founded by an artist collective in 2011, Trampoline House is an independent community space located in Copenhagen. According to its website, it offers an opportunity for refugees and asylum seekers in Denmark to find 'a place of support, community, and purpose'. ${ }^{1}$ While the House's official materials do not specifically use the language of conviviality, its emphasis on mutual participation, integration, and social justice is clear in its mission statement, which reads in part: 'Trampoline House is a community center for asylum seekers, refugees and other citizens in Denmark. Our vision is 
an asylum and integration system where everyone can work, live and participate in society'. In order to work towards this vision, Trampoline House largely relies on donations and crowdfunding by its users and sympathetic members of Danish society, as its small government stipend ended when the most recent, conservative government came to power.

The House sits in the historically diverse neighbourhood of Nørrebro, which is rather centrally located in Copenhagen, but nevertheless far from many of the centres where refugees and asylum seekers live while waiting for decisions on their cases. ${ }^{2}$ Nørrebro's linguistic landscape is varied, Arabic and Farsi script found at regular intervals alongside Danish and English. Independent stores and restaurants run by immigrant shopkeepers sit next to Danish-owned businesses. Several shops around Nørrebro attract a mainly immigrant clientele, which patronises them for specific goods not found in typical Danish markets. Other spaces reveal a mingling of autochthonous Danes and people who have arrived more recently. Multilingual street art marks Nørrebro as something both unique and still very much tied to the Danish capital's cityscape. In this neighbourhood where 'individual memories and the collective memory permeate each other', residents and pedestrians may experience how the city is a medium through which they negotiate their relationships to Denmark and to each other (Chikamori 2009: 153).

This is also the case at Trampoline House. The House is tucked away on a quiet street a couple of blocks from the main thoroughfare through Nørrebro. While this 'politics of place' might suggest a boundary marking (Peattie 1998) that keeps this particular space away from the literal mainstream of the neighbourhood, in many ways Trampoline House offers a microcosm of a vision for an integrated Danish society. New arrivals mingle with and work alongside young European volunteers, who are often also students researching migration. The space is colourful in every sense: banners and posters hang on the walls, plates of food from around the world are laid on the long communal tables at mealtimes, the back garden is painted in patchworks of bright colours and graffiti script, and community members converse by speaking several languages at once while playing games or chatting in the main room. This is not only solidarity, but more specifically 'solidarity with space' (Amin 2008), a conviviality predicated on civic formation in public spaces. The space of the House acts as a medium in the sense that it represents the community using it, and in how it mediates between their various identities, commitments, and experiences, a fact on which I will extrapolate in what follows. 


\section{Conviviality as an Ethical Position}

In my capacity as the photography intern at Trampoline House for over half a year, I was charged with capturing the space and producing various media texts about it. In that time, I was afforded the chance to get to know many of the people who use the space, both new arrivals and Europeans. I initially came to the House for both political and research purposes, and while I considered myself fairly sensitive to issues of migration and media, the House's requirements around access and representation enforced an ethical position that I still find helpful in my current work.

While all are welcome (there is no sign-in sheet at the entrance, and access is based on trust), Trampoline House users must concretely contribute to its everyday life in order to enjoy access. This rule applies especially to volunteers, usually young Danes or other Europeans, who must commit to a certain number of hours every week. For prospective researchers, the expectations are more stringent, with three months of regular service required before one can approach the House with a proposed project. Investments of time and money (volunteers, interns, and researchers are all expected to become monthly donors to the House), as well as demonstrated commitment to the life of the House, act as safeguards against opportunistic research and as a counterbalance to the 'research fatigue' that has set in around migrant populations. The goal of this shared performance of the daily is that all members of the community, regardless of legal status, will experience and participate in an integrative space. That is, while refugees and asylum seekers might find help integrating through their interactions at the House, so too do young Danes and other Europeans get integrated into the idea of a new way of being in the world and part of a convivial milieu. These transformations are predicated in part on the fact that all members of the community move between various communities to participate in the work of Trampoline House.

New arrivals travel between asylum centres or other residential spaces to Trampoline House, a journey that requires a significant amount of time and labour: they must negotiate transportation systems in a new language, for example, and move through spaces which are not always sympathetic to migrants. Many European participants also travel to spend time at the House, moving to Copenhagen because of their interest in its projects, and using the city's public transportation to make their way deep into Nørrebro on a regular basis. Several of these volunteers noted that they had not spent much time in the neighbourhood, past its rather gentrified and hip outer 
blocks. Coming into Nørrebro revealed another part of the city to them, a part that is officially demarcated as a 'ghetto' by the Danish state. ${ }^{3}$ For many new arrivals, the House represents a safe space where they do not have to perform as 'good immigrants', where they can get free legal help and counselling, and where they do not necessarily have to translate their experience to others, as the varied experiences of migration are familiar to most community members.

Capturing these everyday interactions made up much of the work I did at the House during my three-month trial period. The images of meetings, parties, classes, workshops, and other activities that I captured on film show Trampoline House as the convivial space it aspires to be. Many of these images were destined for the House's publicity campaigns. In considering such formal elements as camera angle, lighting, and subject matter, I participated in the visual production of a particular conviviality. In the moments both before and after I snapped the photographs, however, the convivial registered differently.

Because of users' often marginal positionalities, each snapshot required both preamble and epilogue. I approached participants deliberately, as dictated by the House's guidelines for photographers and videographers (which were provided to me at the start of my work), and then asked if I could photograph them in the midst of their activities. Sometimes people bowed out, leaving the frame, or requested that only non-identifying body parts be included. After taking a few shots, I reviewed them with those in the frame, as well as those who might be in the background. Once I uploaded them into the House's secure database, other staff members checked through them, a helpful secondary measure, as sometimes I neglected to account for the statuses or wishes of people who might be passing through the frame as I took the photograph. Many of these colleagues were more familiar with the community than I was and were able to identify people whose legal statuses might be compromised by posting their images on digital media.

Even in this publicity work, there was a keen sense of prioritising collaboration with new arrivals. House members had a clear role in directing photography and thus in determining how they and their space were represented. This element of co-production is central both to the workings of Trampoline House and, as we will see below, to a methodology based on conviviality. 


\section{Conviviality as Co-production}

Trampoline House is meant to be a truly public, convivial space, which belongs neither to native Danes, nor to new arrivals, but is actively produced by their work in concert with each other. The House staff have developed a 'praktik' programme as one way to nurture this production and to combat the charity model of social support, which they deem patronising. ${ }^{4}$ In the context of the asylum centres, praktik involves inhabitants' contribution to centre maintenance by way of menial labour like cleaning up rubbish or sweeping up cigarettes. At Trampoline House, praktik takes on a convivial colour, shaped as it is around such activities as cooking evening meals, caring for the community garden, and taking a language class, or using specialised skills to offer classes or services (e.g. a sewing workshop or childcare $).{ }^{5}$ In exchange for committing to a series of these tasks each week, new arrivals have their transportation fare paid from the asylum centres to Trampoline House. After my internship ended, I volunteered for a while on the cleaning team. Twice a week, the team would do a thorough job of vacuuming, dusting, washing floors, and cleaning bathrooms. While the praktik system could certainly be characterised as a coercive measure to ensure participation, individuals with whom I spoke often noted that the regularity of praktik helped them to make new friends and to feel that they themselves were integral to the production of the space.

The House also functions as an educational opportunity for the larger public. Trampoline House's Centre for Art on Migration Politics (or CAMP, a reclamation of a key signifier of the nation-state's response to migration) is a space for art that directly deals with issues of displacement and migration. ${ }^{6}$ It hosts work by established international artists and newer ones, especially those with refugee or migrant experiences. De-colonizing Appearance (2018), an exhibition curated by US media scholar Nicholas Mirzoeff, for example, drew crowds to its opening and other events and continues to be visited by school groups. Mirzoeff's involvement in the project and subsequent visits to asylum centres in Denmark prompted him to write a piece in The Nation which was widely shared across media platforms and drummed up solidarity for a critique of Denmark's inhumane migration policies. CAMP's contributors and curators thus envision it as a venue through which those with and without these experiences might connect and perhaps find inspiration for new modes of addressing the needs of refugees, asylum seekers, and migrants. 
The House makes an effort to demonstrate and humanise these needs through its online media work, which includes posts on its Instagram and Facebook accounts. Most of the images of House users are taken for publicity purposes-both to encourage participation and as visual material cultivated to encourage financial support by private individuals and larger partner organisations. Along with two colleagues, both Danish MA students studying migration, I noticed that users were seldom afforded the opportunity to represent themselves. We thus began a project to produce a series of portraits for the Trampoline House website. For this project, participants (both new arrivals and European members) were asked to bring a single object with them to the interview. There were no guidelines other than that participants should be willing to tell the story of the object and to have it photographed, even if they did not want to be in the photographs themselves. References to migration were intentionally left out of preliminary discussions so as not to obligate participants to rehearse again the stories of their coming to Denmark and their (often ongoing) movements through the asylum system. The resulting conversations, often held with interpreters' help, focused instead on the stories evoked by the objects. The recording was transcribed and edited for clarity and conciseness, and participants were given a draft before it was to be published, to ensure narrative fidelity.

As will be explained, this project did not continue beyond the first few interviews, and the iterative process deployed in these representations continues to be reproduced, in part, on Trampoline House's Instagram account and on its website. Current interns and volunteers post profile pieces of House users on a semi-regular basis, although the focus is very much on the experience of migration from the perspective of new arrivals and volunteers, rather than on topics or stories of the respondents' choosing.

Trampoline House maintains an active online presence, its regular Instagram and Facebook posts documenting members' activities, which include hanging out at the House, participating in cultural activities hosted at the House, and also taking part in political demonstrations in various Copenhagen neighbourhoods. Members of the community 'like' and comment on these posts and respond to each other, thus continuing the co-production of conviviality in cyberspace. They share articles and add personal anecdotes to posts about demonstrations or developments in immigration legislation. These posts do the work of bridging physical spaces in which House members participate in daily life and the online world where they can revisit and 
add to these memories, or catch up on each other's lives. Even if they cannot visit with each other in person, members can access a mediated image of their togetherness and make it their own.

Indeed, this participatory imagining is central to Trampoline House's project: by focusing on the collaborative, everyday production of the community, the House nurtures a network that (even as the majority of community members remain in limbo) actively imagines the future. By continually reasserting the possibility of a radical democratic imaginary, community members find the revolutionary in their daily practice. Their space is, by their own description, a microcosm of what they hope to see happen in the larger culture: co-existence built through trust, collaboration, co-production, and creativity.

\section{Conviviality ANd Conflict}

Nevertheless, the fact remains that Trampoline House's core staff is a small team, whereas the larger group of interns and volunteers is a rotating cast, while the asylum seekers and refugees who participate in the House may do so for years while they wait for a decision on their cases. When Gilroy (2004) imagines spaces of conviviality, his sense of time is in some ways limited by his focus on the persistence of melancholia, to which conviviality is the antidote. However, different groups of people experience time-the waiting, the breakthrough, the disappointment, and the hurry-in different ways. The researchers, interns, and volunteers who cycle through the House have produced numerous MA theses, news articles, long-form essays, etc. Thus, at the same time that the House combats research fatigue by regulating who can research and when, this impermanence also brings up new questions regarding the sustainability of conviviality. Specifically: Can conviviality be something that is produced, renewed, sustained, even in unstable, changeable situations?

Although it may seem paradoxical, the conviviality found in Trampoline House is bound up not only with practices of mutuality, but also with experiences of conflict. Regular participants - refugees and asylum seekers, as well as autochthonous Danes and other Europeans - share similar quarrels with the state's handling of asylum cases and are united in their mission to combat the xenophobia that attends, and is provoked by, state policy. In fact, the conflict in which all participants find themselves provides the material for continued social justice work and campaigns and forges the 
House's connections with likeminded organisations. Members of Trampoline House march through Copenhagen as part of larger demonstrations demanding things like educational access for the children of asylum seekers and better conditions in the centres, especially in the notorious deportation centre Sjælsmark. Weekly meetings serve as a place for members to air any grievances or concerns and to generate energy for upcoming demonstrations and campaigns. Likewise, the lawyers and therapists on hand at the House offer counsel as new arrivals navigate a frequently opaque and brutal immigration system.

Rarely has conflict emerged as a divisive force within Trampoline House, despite the fact that many members represent groups that might experience conflict in their home countries. During my time at Trampoline House, however, I found myself in the thick of one. The way in which members tried to mediate this conflict is instructive.

Trampoline House hosts a party on the first Friday of each month. Early in the evening, people gather to hear a speaker or take part in a workshop. A community meal is served, and after the plates are cleared away, the lights go down, and Goody, the House's resident DJ, slips behind his decks. The mix of dance music ranging from 1980s American tunes to Kurdish pop makes for a lively party, one in which House members of all stations take part.

I attended several of these festivities as part of my research and my personal engagement with Trampoline House. It was at one of them, in Fall 2017, that I was assaulted in an empty hallway by a member of the House, who had taken my dancing with him as an invitation to kiss me. When I tried to break free of his grip, he wrapped an arm around my neck and pulled me to him, refusing to let go and trying to turn me to face him. I was finally able to manoeuvre out of his grip and find one of the House directors. She asked me to sit down and talk with him on the spot, an injunction I refused, after which she approached him and asked him to meet her at the front of the House to talk about what had happened. He agreed but promptly disappeared from the premises. The staff member told me she would speak to him when next she saw him and encouraged me to 'take it as a compliment' in the meantime.

This initial attempt at mediation in the immediate aftermath of the assault felt obviously insufficient. At the next weekly staff meeting, I relayed this experience to the staff, volunteers, and interns. The staff member admitted her role in the incident and explained her reaction as a social justice-motivated response which forced her to consider whether I or he 
needed the House more. Most, though not all, members in attendance reacted negatively to this justification, and the meeting lasted an hour longer than usual as other women-identified members of the community came forward with their own stories about feeling uncomfortable or threatened at the House.

This particular conflict and the ensuing conversation provoked a series of changes at the House, beginning with a community-generated set of guidelines for social interaction, which was drawn up at a weekly House meeting. My assailant was taken aside by male staffers later that day, and he agreed to stay away from the House for a period of one month. Thus, while the conflict registered firstly as divisive, its outcome provided further material around which Trampoline House's convivial ethos could cohere.

Yet the incident also gave me pause in terms of my research and especially in terms of my methods as an ethnographer. While I felt buoyed by the community's response, and from the changes that became evident in the House, I experienced two other reactions as well. First, although I know that assault is never the victim's fault, I nevertheless harboured a sense of guilt for being part of a situation that precipitated this man's having to leave the House, even for a short while. Secondly, I wondered about my own participation in the House going forward: Would I feel the same closeness with people there and especially with this man's friends? Would they feel the same closeness with me? Would the aftermath of the incident shift the feeling in the House, and if so, would it be better to continue or to leave? How had this incident - and my narration of it - marked the fabric of this co-produced space? What effect had it had on my ethical stance, as researcher and activist? Could I still inhabit those roles in the same way? How would the memory of it mediate the feelings I and others had about the House, in terms of our safety and how this figured (or did not) in its mission?

These questions lingered, even as I dimly realised I was drifting away from Trampoline House. In subsequent months, I heard from other former members who had similar experiences, and who had decided to leave the House, and communicated with me via email and Facebook. Their decisions were difficult and painful and not made without a good deal of consideration. These members, mostly paid staff and interns who were also researchers, remain ethically and politically committed to the well-being of migrants and in their jobs and volunteer work continue to join their conflict with exclusionary and harmful state practices. However, they felt, as I did, that the ethical imperatives of engagement sometimes must be gauged 
against questions of personal safety and a real consideration of whether an organisation is truly committing to co-production, fair representation, and social justice, rather than merely rehearsing charitable actions that the House itself apparently understands as potentially patronising.

Our conversations, and indeed these conflicts, continue to unfold even as I write this chapter, and to be mediated both through our digital communication and by our shared experiences of Trampoline House in its best and worst moments. We have shared our writing with each other and met in person in Copenhagen to talk through what might come next, in terms of our research, activism, and participation in the House. We feel the pull of our personal commitments to our friends there and our ethical commitments to the House's mission, and at the same time, we recognise an ethical commitment to a conviviality realised through social justice aspirations, mediated conflict, and a research imperative that is truly co-productive.

\section{CONCLUSION}

This chapter has argued for seriously considering conviviality as an imperative and horizon of research in media and migration. In discussing the methodological potential of the term, I have suggested that it is precisely the combination of its normative properties and its embrace of conflict, as debated in previous literature, that makes it useful to social justice-oriented research. Through anecdotes from the field, I have further highlighted three emphases of conviviality that are particularly useful in ethnographic contexts: an ethical stance, co-production, and conflict.

In discussing the interplay between various convivial spaces, both physical and digital, and my role in producing representations with my interlocutors, I have tried to account for the ways in which my fieldwork at Trampoline House challenged me to take an ethical stance as both an activist and a researcher. Over time, however, it became clear to me and other activists and researchers that the House is still figuring out how best to mediate conflict.

And this is part of the process.

I began this chapter on a hopeful note which perhaps seems diminished in light of the last section on the conflicts endured by Trampoline House staff members. However, these conflicts ought not to deter us from deploying conviviality, or from working towards it in our research as in our activism. Conviviality is a horizon rather than a destination, a process of 
frustrating but dynamic everyday growth which we would be foolish to try to force into a linear progression.

Life goes on at the House without the presence of the researchers and activists who left. Digital and physical lives still mediate the different communities at work in its daily activities. There will be more House meetings and events responding to Denmark's changing political and social landscape and the realities of new arrivals. The activists and researchers who made the decision to leave continue the dialogue of what it means to live together, to work together towards equal participation in society, and to deal deliberately and sensitively with conflict. We are still discussing the lessons - not least of all the ones that were hard to learn-with each other and will carry these questions forward in our work.

To simply look for conviviality as something to be observed or measured, conceptually debated or analysed, is not enough. Researchers and activists alike must instead work harder to engage interlocutors in the coproduction of media representations, safe spaces, and convivial community. It is imperative that we do so. As the political landscape continues to shift around the world, research and activism that imagines, deploys, and works towards the convivial-in its capacity for hope as well as conflict-will be essential tools in combating the stigma and hostility that beget and are encoded in violent immigration policy.

Acknowledgment Many thanks to Tina Askanius and Tobias Linné for help with early drafts of this chapter.

\section{Notes}

1. For more, please visit: https://www.trampolinehouse.dk.

2. Danish readers will be interested in Garbi Schmidt's (2015) work on the neighbourhood's immigration history, Nørrebros indvandringshistorie $1885-2010$.

3. For more on this topic, please see https://www.nytimes.com/2018/07/01/ world/europe/denmark-immigrant-ghettos.html.

4. While it is beyond the scope of this chapter to discuss the differences between charity and activism (which are politically and social contextual and also vary between academic fields), it is worth noting that all new interns and volunteers at Trampoline House are told that the 'charity model' of social support (in which funds are distributed to those in need, or events are held to raise money for them) is not sustainable. Rather, each person-volunteer, intern, and migrant-should shoulder part of the responsibility of the House as part of their empowerment. This sentiment is displayed in 
an account written for France24 (2017) by Trampoline House founder Morten Goll. https://observers.france24.com/en/20170404-copenhagentrampoline-house-refugee-integrate.

5. It should be noted that language classes offered by the state are often given at time inconvenient to asylum-seeking and refugee families, mainly in the evening, when parents would need childcare to take these classes, but cannot find/afford it.

6. Visit https://www.trampolinehouse.dk/about-camp/ for more details.

\section{REFERENCES}

Abid, Z. R., A. S. Manan, and Z. A. A. A Rahman. 2017. “'A Flood of Syrians Has Slowed to Trickle': The Use of Metaphors in the Representation of Syrian Refugees in the Online Media News Reports of Host and Non-Host Countries." Discourse o Communication 11 (2): 121-140. https://doi.org/ $10.1177 / 1750481317691857$.

Alhourani, A. R. 2017. "Performative Ethnography: Difference and Conviviality of Everyday Multiculturalism in Bellville (Cape Town)." Journal of African Cultural Studies 29 (2): 211-226. https://doi.org/10.1080/13696815.2016. 1273764.

Amin, A. 2008. "Collective Culture and Urban Public Space." City 12 (1): 5-24. https://doi.org/10.1080/13604810801933495.

Berry, M., I. Garcia-Blanco, and K. Moore. 2015. "Press Coverage of the Refugee and Migrant Crisis in the EU: A Content Analysis of Five European Countries." Report Prepared for the United Nations High Commission for Refugees, December. Available from https://www.unhcr.org/56bb369c9.pdf. Accessed May 3, 2019.

Caviedes, A. 2015. "An Emerging 'European' News Portrayal of Immigration?” Journal of Ethnic and Migration Studies 41 (6): 897-917. https://doi.org/10. 1080/1369183x.2014.1002199.

Chandler, D., and R. Munday. 2016. A Dictionary of Media and Communication. Oxford: Oxford University Press.

Chikamori, T. 2009. "Between the 'Media City' and the 'City as a Medium."” Theory, Culture and Society 26 (4): 147-154. https://doi.org/10.1177/ 0263276409104972.

Dekker, R., and G. Engbersen. 2014. "How Social Media Transform Migrant Networks and Facilitate Migration." Global Networks 14: 401-418. https://doi. org/10.1111/glob.12040.

Fabian, J. 1990. Power and Performance: Ethnographic Explorations Through Proverbial Wisdom and Theatre in Shaba, Zaire. Madison: University of Wisconsin Press. 
Fabian, J. 1995. "Ethnographic Misunderstanding and the Perils of Context." American Anthropologist 97 (1): 41-50. https://doi.org/10.1525/aa.1995. 97.1.02a00080.

Frouws, B., M. Phillips, A. Hassan, and M. Twigt. 2016. "Getting to Europe the Whatsapp Way: The Use of ICT in Contemporary Mixed Migration Flows to Europe." Report Regional Mixed Migration Secretariat. Available from http://reliefweb.int/report/world/briefing-paper-2-gettingeurope-whatsapp-way-use-ict-contemporary-mixed-migration-flows. Accessed May 3, 2019.

Gabrielatos, C., and P. Baker. 2008. "Fleeing, Sneaking, Flooding: A Corpus Analysis of Discursive Constructions of Refugees and Asylum Seekers in the UK Press, 1996-2005." Journal of English Linguistics 36 (1): 5-38. https://doi. org/10.1177/0075424207311247.

Gillespie, M., L. Peter Ampofo, M. Cheesman, B. Faith, E. Illiou, A. Issa, S. Osserian, and D. Skleparis. 2016. "Mapping Refugee Media Journeys Smartphones and Social Media Networks." Report The Open University/France Médias Monde. Available from http://www.open.ac.uk/ccig/sites/www.open.ac. uk.ccig/files/Mapping\%20Refugee\%20Media\%20Journeys\%2016\%20May\% 20FIN\%20MG_0.pdf. Accessed May 3, 2019.

Gilroy, P. 2004. After Empire: Melancholia or Convivial Culture?-Multiculture or Postcolonial Melancholia. New York: Routledge.

Gilroy, P. 2006. Postcolonial Melancholia. New York: Columbia University Press.

Greussing, E., and H. G. Boomgaarden. 2017. "Shifting the Refugee Narrative? An Automated Frame Analysis of Europe's 2015 Refugee Crisis." Journal of Ethnic and Migration Studies 43 (11): 1749-1774. https://doi.org/10.1080/ 1369183x.2017.1282813.

Houssein, C. 2013. "Diaspora, Memory, and Ethnic Media: Media Use by Somalis Living in Canada." Bildhaan: An International Journal of Somali Studies 12 (11): 87-105.

Kittler, F., and M. Griffin. 1996. “The City Is a Medium.” New Literary History 27 (4): 717-729.

Lapiņa, L. 2016. “Besides Conviviality: Paradoxes in Being 'at Ease' with Diversity in a Copenhagen District". Nordic Journal of Migration Research 6 (1): 33-41. https://doi.org/10.1515/njmr-2016-0002.

Lawlor, A. 2015. "Local and National Accounts of Immigration Framing in a CrossNational Perspective." Journal of Ethnic and Migration Studies 41 (6): 918-941. https://doi.org/10.1080/1369183x.2014.1001625.

Lulle, A., and E. Ungure. 2015. “Asylum Seekers' Crisis in Europe 2015: Debating Spaces of Fear and Security in Latvia." Journal of Baltic Security 1 (2): 62-95. https://doi.org/10.1515/jobs-2016-0021.

Marcus, G. E. 1998. Ethnography Through Thick and Thin. Princeton, NJ: Princeton University Press. 
Matthews, J., and A. R. Brown. 2012. "Negatively Shaping the Asylum Agenda? The Representational Strategy and Impact of a Tabloid News Campaign." Journalism Criticism, Theory and Practice 13 (6): 802-817. https://doi.org/10. $1177 / 1464884911431386$.

Musarò, P., and P. Parmiggiani. 2017. "Beyond Black and White: The Role of Media in Portraying and Policing Migration and Asylum in Italy." International Review of Sociology 27 (2): 241-260. https://doi.org/10.1080/03906701. 2017.1329034.

Nowicka, M., and T. Heil. 2015. "On the Analytical and Normative Dimensions of Conviviality and Cosmopolitanism." Lecture held on 15 June at the Eberhard Karls University Tübingen, Germany.

Parker, S. 2015. “'Unwanted Invaders': The Representation of Refugees and Asylum Seekers in the UK and Australian Print Media." Myth and Nation 23: 1-21.

Peattie, L. 1998. "Convivial Cities." In Cities for Citizens: Planning and the Rise of Civil Society in a Global Age, edited by M. Douglass and J. Friedmann, 247-252. Chichester: Wiley.

Schmidt, G. 2015. Nørrebros indvandringshistorie 1885-2010. Copenhagen: Museum Tusculanum.

The Observers/France24. 2017. “Copenhagen's 'Trampoline House' Helps Refugees Integrate." Available from https://observers.france24.com/en/ 20170404-copenhagen-trampoline-house-refugee-integrate. Accessed June 7, 2019.

Van Gorp, B. 2005. "Where is the Frame?" European Journal of Communication 20 (4): 484-507.

Varjú, V., and S. Plaut. 2017. "Media Mirrors? Framing Hungarian Romani Migration to Canada in Hungarian and Canadian Press." Ethnic and Racial Studies 40 (7): 1096-1113. https://doi.org/10.1080/01419870.2017.1266007.

Venegas, K., and A. Huerta. 2010. "Urban Ethnography: Approaches, Perspectives and Challenges." In New Approaches to Qualitative Research: Wisdom and Uncertainty, edited by M. Savin-Baden and C. Howell Major, 154-161. New York: Routledge. 
Open Access This chapter is licensed under the terms of the Creative Commons Attribution 4.0 International License (http://creativecommons.org/licenses/by/ $4.0 /$ ), which permits use, sharing, adaptation, distribution and reproduction in any medium or format, as long as you give appropriate credit to the original author(s) and the source, provide a link to the Creative Commons license and indicate if changes were made.

The images or other third party material in this chapter are included in the chapter's Creative Commons license, unless indicated otherwise in a credit line to the material. If material is not included in the chapter's Creative Commons license and your intended use is not permitted by statutory regulation or exceeds the permitted use, you will need to obtain permission directly from the copyright holder.

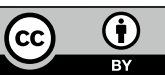

